\title{
La dialectología gallega
}

\author{
MANUEl RodRíGUEz Alonso
}

INSTITUTO MARIANO JOSÉ DE LARRA

Los padres Sarmiento y Sobreira pueden ser considerados los iniciadores de la dialectología gallega en el siglo XVIII. Las ediciones y los estudios del profesor Pensado nos han permitido conocer estas labores de Sarmiento y de Sobreira. (Véanse las ediciones del profesor Pensado de Sarmiento: Catálogo de voces y frases de la lengua gallega. Salamanca. Universidad de Salamanca. 1973/ Colección de voces y frases gallegas. Salamanca. Universidad de Salamanca, 1970. También Pensado Tomé: Opúsculos linguiisticos del siglo XVIII, Vigo. Fundación Penzol-Galaxia, 1974). Sarmiento recoge el léxico gallego de su tiempo y además establece las zonas en que son de uso las palabras que explica: "Zunchos. Llaman así en Vivero a las castañas cocidas con cáscara, y en Pontevedra mamotas." (Catálogo..., página 324). Así pues, Sarmiento no sólo recoge el vocablo, sino que lo sitúa espacialmente, con lo cual se adelantaba a las técnicas de las modernas dialectología y geografía lingüística.

Sarmiento en su obra también hace referencia a otro de los fenómenos característicos de la dialectología gallega: el seseo. Cita también la gheada e incluso alude a los resultados de -anu, -ana, señalando que la conservación de la ene es propia de la provincia de Pontevedra y de la marina mientras que su pérdida caracteriza a las tierras interiores de Galicia (V. Santamarina, A.: "Dialectoloxia galega: estudios e resultados." En Kremer, D. e Lorenzo, R. [eds.]: Tradición, actualidade e futuro do galego. Actas do Coloquio de Tréveris. Santiago de Compostela. Xunta de GaliciaConsellería de Cultura, 1982, pág. 156.) En definitiva, por lo visto Sarmiento parecía ya distinguir entre un gallego atlántico y costero y otro interior y continental.

Sobreira también señala aunque de modo asistemático distintas variedades de la lengua gallega, pero, claro es, sin someterlas a una regularización o sistematización. Así señala como propio de la zona de Pontevedra el seseo o 
señala la existencia de la gheada por distintos lugares. (Santamarina, loc. cit., págs. 157-158).

Aunque asistemáticos, Sarmiento y Sobreira fueron pioneros en el establecimiento de unas diferencias dialectales en el gallego y resulta interesante la intuición del primero en el sentido de establecer una especie de divisoria entre un gallego atlántico o costero y un gallego interior o continental.

\section{LA DIVISIÓN DIALECTAL DE SACO Y ARCE}

Cuando se inicia en el "Rexurdimento" la recuperación de la lengua y de la cultura gallegas hay también un tímido florecer de estudiosos del idioma y gramáticos: Pintos, Valladares, Saco...

La idea de los ilustrados dieciochescos sobre la existencia de diferentes variedades geográficas o dialectales del gallego sigue presente en estos pioneros de la gramática y la linguística gallegas. En 1853, Pintos, en su célebre $A$ Gaita Gallega, reconoce implícitamente la existencia de variedades dialectales cuando propone que para la formación de un gallego estándar lo mejor sería la reunión de "... catro galleguiños / Das catro esquinas do reino / Que cuiden de recollelo / De compolo e arrombalo, / e facer un todo inteiro"/ (Pintos, X. M.: A Gaita Gallega... La Coruña. Voz de Galicia, 1981. Edición facsímil de la de 1853 , página 37 ).

Sin embargo, va a ser Saco y Arce, en 1868, en su célebre gramática el que establezca una clara división del gallego en lo que él llama subdialectos. Saco advierte antes de nada sobre la gran unidad del gallego pero que a pesar de ello "ofrece no obstante diferencias locales de no mucha importancia, que dan origen a otros tantos subdialectos" (Saco y Arce: Gramática Gallega. Orense. Gráficas Tanco, 1967, pág. 120). Saco, después de señalar que puede haber tantos subdialectos como provincias los reduce a dos: el septentrional y el meridional. Saco establece esta división utilizando tres criterios: pronunciación de las vocales más abiertas por el dialecto del norte, gusto especial del dialecto norteño por la $n$ que mantiene la terminación - an frente a la sureña - ao y por último, el dialecto meridional gusta de la contracción de las vocales en contacto mientras que el septentrional prefiere el hiato. Saco ejemplifica estas diferencias entre subdialecto septentrional y meridional con unas pedagógicas tablas comparativas de ejemplos. 
Gallego septentrional

aquí, ahí, alí, así
perdeches
recebeu
el, eles
froito, loito
mañán, chan, man
uns, cans, ilusións
a os homes

\section{Gallego meridional}

\author{
eiquí, ehí, elí \\ perdiches \\ recibiu \\ il, iles \\ fruto, luto \\ mañá, chao, mau \\ us, cas, ilusiós \\ ôs homes
}

(Saco, ob. cit., págs. 190-191.)

Saco también señala el seseo como propio del gallego septentrional. Sin embargo, Saco realiza la primera división dialectal de Galicia y sigue manteniendo una clara división entre dos tipos de gallego, que ya no son el atlántico y el continental, como parecía sugerir Sarmiento, sino el septentrional y el meridional. No es científica la división, como se comprende a simple vista, pues las provincias de Orense y Pontevedra se caracterizarian por tener el mismo tipo de dialecto, o Lugo y La Coruña. Parece ser que la división dialectal de Saco obedece a la simple oposición de las dos hablas locales que conocía bien y de primera mano: la de Orense (meridional) y la de Santiago de Compostela (septentrional) (Vid. Santamarina, A. ., página 160$)$.

\section{LAS DIVISIONES DIALECTALES DEL SIGLO XX ANTERIORES A 1971}

Creemos oportuno dividir los estudios y las clasificaciones dialectales en dos épocas en este siglo: antes y después de la creación del Instituto da Lingua Galega. Hasta la creación del Instituto da Lingua Galega, en la entonces Facultad de Filosofía y Letras de la Universidad de Santiago de Compostela, no se había emprendido un estudio metódico de las variedades dialectales del gallego. Con la creación de este centro empieza el estudio metódico de la realidad lingüística gallega y fundamental para los estudios de dialectología y geografía lingüística: es la elaboración del Atlas Lingüístico de Galicia bajo la dirección de los profesores C. García y A. Santamarina y con tres encuestadores: Álvarez Blanco, Fernández Rei y González González. En el año 1991 se publicó el primer volumen de este atlas, el correspondiente a la morfología verbal. Por ello, es conveniente el éstablecer un antes y un después de 1971. 


\subsection{Los estudios dialectai.es de García de Diego}

En 1909 García de Diego publicó sus Elementos de gramática histórica gallega, en Burgos. (Citamos por la edición facsímil de M. Taboada. Santiago de Compostela. Verba, anexo 23. Universidad de Santiago de Compostela, 1984.) García de Diego se enfrenta al problema de la división dialectal del gallego con prudencia pues señala en el apartado Variantes locales de su gramática: "... no se han hecho estudios minuciosos, así que las observaciones que aquí pongamos han de ser muy someras e incompletas" (pág. 155). García de Diego en este apartado denominado "Variantes locales" (págs. 155-158) estudia fenómenos como los resultados de -anu, - ana (man / mau, mañán / mañá, irmán / irmau), los plurales de los sustantivos y adjetivos terminados en -n (pantalóns / pantalós), la distribución tu / ti del pronombre personal de segunda persona, el seseo... Curiosamente, la gheada la señala de paso y sin darle mayor importancia. Sin embargo, García de Diego no realiza una división del gallego en grupos dialectales y señala: "Las diferencias que ofrece el gallego en sus diversas regiones no son tan profundas para poder constituir grupos dialectales" (García de Diego, ob. cit., pág. 155).

\subsection{La diVISIÓN dialectal de Zamora ViCEnTE}

Zamora Vicente en el año 1953 va a distinguir dos subdialectos en su artículo "De geografía dialectal: -ao, -an en gallego" (en Nueva Revista de Filología Hispánica. México-Caracas. Colegjo de México/Universidad Central de Venezuela, págs. 73-80. Figura también en Zamora Vicente, A.: Estudios de dialectología hispánica. Santiago de Compostela. Verba. Anexo 25. Universidad de Santiago de Compostela, 1986, págs. 27-34). Zamora usando tres rasgos (el resultado de -anu, -ana latinos; el seseo y la gheada) distingue una variedad oriental o continental caracterizada por el resultado - ao, a (irmau) de -anu y la ausencia de seseo y gheada (cegar) y una variedad occidental o atlántica con resultado -án (irmán), seseo y gheada ("segho").

\subsection{La división dialectal. de Carbal.lo Calero}

A partir de la división de Zamora, Carballo Calero va a establecer cuatro áreas o variedades dialectales del gallego en su artículo "Sobre os dialectos do gallego" (en Grial, 23, 1969, Vigo, págs. 1-15. Carballo recoge también 
este artículo en el libro Sobre lingua e literatura galega. Vigo. Galaxia, 1971, págs. 211-228). Carballo para establecer sus cuatro modalidades usa nueve rasgos; resultados -án, -á y -ao de -anu latino; resultados -á, -án de -ana latino; formación de plural en los sustantivos terminados en - $n$ : cans, cas, cais; ladróns, ladrós, ladrois; plural de los sustantivos terminados en - $I$ : animás, animais; resultados de -inu: paxariño, paxarín; tipos de ese: apical o predorsal; ausencia o presencia de seseo: moza, mosa; resultados de - ce final latina: lus, luz; ausencia o presencia de gheada: aghulla, agulla. Combinando estos rasgos surgen para Carballo cuatro áreas dialectales: Suroccidental, Noroccidental, Central y Oriental. Carballo en un cuadro muy pedagógico los ejemplifica así:

Suroccidental: irmán, irmán, cans, animás, paxariño, $s$ predorsal, mosa, lus, aghulla.

Noroccidental: irmá, irmá, cas, animás, paxariño, $s$ apical, moza, lus, aghulla.

Central: irmao, irmá, cas, animás, paxaríño, $s$ apical, luz, moza, agulla.

Oriental: irmao, irmá, cais, animais, paxarín, s apical, luz, agulla.

\section{LA DIALECTOLOGÍA GALLEGA POSTERIOR A 1971}

La fundación del ILG (Instituo da Lingua Galega) en 1971 y la elaboración del Atlas Lingüístico de Galicia, como ya señalamos, propició un mejor conocimiento de la realidad dialectal del gallego, que ha cristalizado en los estudios de Fernández Rei.

\subsection{Bloques y áreas del gallego seglún Fernández. Rei}

Fernández Rei fue uno de los tres encargados de realizar las encuestas del Atlas Lingüístico de Galicia. Fruto de esta experiencia son distintos artículos publicados a partir de 1980 sobre diạlectología gallega y especialmente su Dialectoloxía da lingua galega (Vigo. Xerais, 1990). Fernández Rei vuelve a la vieja posición de García de Diego sobre la unidad del gallego: "O material recolleito para o citado ALGa (Atlas Linguística de Galicia)... faime compartila opinión de García de Diego de que no se pode 
falar de dialectos propiamente ditos no galego." (Ob. cit., pág. 36). Fernández Rei empleando 81 características fonéticas, morfológicas y hasta léxicas establece tres grandes bloques lingüísticos que a su vez divide en áreas, subáreas y microsubáreas. El bloque occidental se caracteriza según Fernández Rei, por rasgos como la gheada, terminación -án, plural -ns (cans, ladróns) y hasta nueve rasgos en total. El bloque central se caracteriza por la presencia de gheada en su occidente y ausencia en el oriente, ausencia de seseo, plural - $s$ en los terminados en -n (cas, ladrós), terminación -ao y no -án (irmao) y así hasta ocho rasgos. El bloque oriental se caracteriza por la terminación -ín del diminutivo (paxarín), el plural -is en los términados en - $n$ y $-l$ (cais, pantalois, animais, caracois) y así hasta ocho rasgos caracterizadores. Cada bloque a su vez se divide en áreas, subáreas y hasta microsubáreas.

La división de Fernández Rei, a pesar de su inicial afirmación sobre la unidad del gallego, nos da la sensación de una lengua excesivamente fragmentada. Podemos decir que se advierte la existencia de dos variantes que no quiebran el sentido de unidad que de su lengua tiene el hablante gallego. Habría una variante occidental o atlántica en la que destacan el plural -ns (pantalóns), la gheada, el seseo, la forma -án (irmán, man) ... y otra continental sin seseo, con -ao,/-au (irmau), plural $-s$ de los terminados en - $n$ (pantalós) ... La primera se caracteriza por ser menos extensa geográficamente pero más vital demográficamente, porque en esta zona se encuentra la mayor densidad de población de la comunidad gallega. En cuanto a la frontera de estos fenómenos no es rígida, aunque la zona atlántica es, en general, sentida como más innovadora, por más que la mayor cultura esté haciendo que retrocedan fenómenos característicos suyos como el seseo o la gheada mientras que en la zona continental no acaban de imponerse formas occidentales elegidas como normativas ( $\mathrm{pl}$. *pantalós, *irmau...).

\subsection{Dialectología y normativa}

Los estudios dialectales del gallego han servido para justificar las elecciones normativas que proponen las Normas Ortográficas e Morfológicas do Idioma Galego del ILG (Instituto da Lingua Galega) y de la RAG (Real Academia Gallega). Se elige la forma literaria, la más extensa, la que está en un área aislada, la que se considera más genuinamente gallega, etcétera, pero siempre comentando las distintas soluciones dialectales, con lo cual el hablante que consulta esta normativa ve reflejadas las características de su habla local, que en ningún caso, son despreciadas, aunque se elija otra variante dialectal. Este es, desde nuestro punto de vista, uno de los aciertos de la actual 
Normativa, porque aunque no se acepte la variante dialectal del consultante, éste se siente reconfortado al ver que ésta no es nunca despreciada por poco extensa, no literaria, etcétera. En este caso, los estudios dialectales no sólo han servido para consulta de eruditos o buscadores de rarezas lingüísticas, y es de justicia el señalarlo. 